\title{
Characterization of Lactobacillus salivarius alanine racemase: short-chain carboxylate-activation and the role of A131
}

\author{
Jyumpei Kobayashi ${ }^{1 *}$, Jotaro Yukimoto ${ }^{2}$, Yasuhiro Shimizu ${ }^{1}$, Taketo Ohmori ${ }^{3}$, Hirokazu Suzuki ${ }^{4}$, Katsumi Doi ${ }^{5}$ \\ and Toshihisa Ohshima ${ }^{1,5}$
}

\begin{abstract}
Many strains of lactic acid bacteria produce high concentrations of D-amino acids. Among them, Lactobacillus salivarius UCC 118 produces D-alanine at a relative concentration much greater than $50 \%$ of the total D, L-alanine (100D/D, $L$-alanine). We characterized the L. salivarius alanine racemase (ALR) likely responsible for this D-alanine production and found that the enzyme was activated by carboxylates, which is an unique characteristic among ALRs. In addition, alignment of the amino acid sequences of several ALRs revealed that A131 of L. salivarius ALR is likely involved in the activation. To confirm that finding, an L. salivarius ALR variant with an A131K (ALR ${ }^{A 131 K}$ ) substitution was prepared, and its properties were compared with those of ALR. The activity of $A L R^{A 131 K}$ was about three times greater than that of ALR. In addition, whereas L. salivarius ALR was strongly activated by low concentrations (e.g., $1 \mathrm{mM}$ ) of short chain carboxylates, and was inhibited at higher concentrations (e.g., $10 \mathrm{mM}$ ), ALR ${ }^{\mathrm{A} 131 \mathrm{~K}}$ was clearly inhibited at all carboxylate concentrations tested (1-40 mM). Acetate also increased the stability of ALR such that maximum activity was observed at $35^{\circ} \mathrm{C}$ and $\mathrm{pH} 8.0$ without acetate, but at $50^{\circ} \mathrm{C}$ in the presence of $1 \mathrm{mM}$ acetate. On the other hand, maximum $A L R^{A 131 K}$ activity was observed at $45^{\circ} \mathrm{C}$ and around $\mathrm{pH} 9.0$ with or without acetate. It thus appears that $\mathrm{A} 131$ mediates the activation and stabilization of $L$. salivarius ALR by short chain carboxylates.
\end{abstract}

Keywords: D-amino acid, Alanine racemase, Lactobacillus salivarius, Lactic acid bacteria, Short-chain carboxylate

\section{Background}

With the exception for glycine, which contains no asymmetric carbon, all proteogenic amino acids exist as $\mathrm{L}-\alpha-$ form molecules. Indeed, up to around 1980, D-amino acids as enantiomers of corresponding L-amino acids were generally considered to have no important role in living organisms, and so attracted little attention, though it was acknowledged that some D-amino acids were among the main constituents of bacterial cell walls (Heijenoort 2001). However, advances in the analytical techniques used to study amino acid enantiomers have shown that, in fact, D-amino acids are widely distributed among a variety of organisms, including plants, fish and

\footnotetext{
*Correspondence: jyumpei.kobayashi@gmail.com

${ }^{1}$ Microbial Genetics Division, Institute of Genetic Resources, Faculty

of Agriculture, Kyushu University, Fukuoka 812-8581, Japan

Full list of author information is available at the end of the article
}

mammals (Kullman et al. 1999; Erbe and Brückner. 2000; Pätzold et al. 2005). In addition, it was recently reported that D-amino acids exert inhibitory effects on biofilm formation (Kolodkin-Gal et al. 2010; Hochbaum et al. 2011). Such evidence of the physiological importance of D-amino acids has prompted investigation into their metabolism and the enzymes involved.

D-Alanine is well known to be a component of bacterial cell walls and to be synthesized from L-alanine by alanine racemase (ALR). Our group recently found that many lactic acid bacteria secrete $\mathrm{D}$-alanine into their medium (Mutaguchi et al. 2013) and the relative percentage $(100 \mathrm{D} /(\mathrm{D}+\mathrm{L}))$ of $\mathrm{D}$-alanine per total $\mathrm{D}$, L-alanine in many lactic acid bacterial cells is more than $50 \%$; the value for Lactobacillus salivarius is $89.6 \%$, for example. ALR is thought to be pivotal for D-alanine production in lactic acid bacteria, but this racemase generally catalyzes the conversion of $\mathrm{L}$-alanine to a racemic mixture, and

\section{㩏 Springer}

(c) 2015 Kobayashi et al. This article is distributed under the terms of the Creative Commons Attribution 4.0 International License (http://creativecommons.org/licenses/by/4.0/, which permits unrestricted use, distribution, and reproduction in any medium, provided you give appropriate credit to the original author(s) and the source, provide a link to the Creative Commons license, and indicate if changes were made. 
the D-alanine percentage does not normally exceed $50 \%$. Thus it may be postulated that an unknown mechanism accounts for the excess $\mathrm{D}$-alanine production seen in $L$. salivarius.

We previously identified a D-amino acid aminotransferase (D-AAT) in L. salivarius that exhibited characteristics different from those of known D-AATs from strains of Bacillus and Geobacillus species (Kobayashi et al. 2013). In that context, we were interested in the inherent characteristics of ALR of L. salivarius and identified an ALR homolog gene in an L. salivarius data base. In the present study, we expressed this L. salivarius ALR gene in Escherichia coli and, interestingly, found that the purified ALR protein was strongly activated in the presence of carboxylates such as acetate and propionate. By contrast, ALRs from Geobacillus and Bacillus species are reportedly inhibited by acetate and propionate (Morollo et al. 1999; Kanodia et al. 2009). In addition, ALRs from L. fermentum and Pseudomonas putida are known to be stabilized by acetate, although the mechanism for this effect is not yet known (Johnston and Diven. 1969; Rosso et al. 1969). We therefore compared the primary sequences of ALRs from L. salivarius, L. fermentum and P. putida with those of various Bacillus and Geobacillus species. Nearly all important residues for the execution of catalytic activity are well conserved, except for a single residue: A131 in L. salivarius, L. fermentum and P. putida ALRs, and K129 in Bacillus and Geobacillus ALRs. K129 is thought to stabilize R136 binding to the carboxylate group through carbamate formation (Morollo et al. 1999). Here we examined the role of A131 in the regulation of L. salivarius ALR by the carboxylates by preparing an $L$. salivarius ALR variant (A131K; $\mathrm{ALR}^{\mathrm{A} 131 \mathrm{~K}}$ ) and comparing its properties with those of the parental wild-type ALR.

\section{Methods}

\section{Sequence analysis of ALR}

The primary amino acid sequence of $L$. salivarius ALR was analyzed and compared with those of previously reported ALRs (Johnston and Diven 1969; Inagaki et al. 1986; Kanda-Nambu et al. 2000; Ju et al. 2009; Kanodia et al. 2009; Liu et al. 2012). The amino acid sequences of L. salivarius UCC118, B. pseudofirmus OF4 and G. stearothermophilus IFO 12550 ALRs were retrieved from the UniProt data base (http://www.uniprot.org/), and that of $P$. putida YZ-26 was obtained from the report by Liu et al. (2012). The sequences of B. anthracis Sterne 34F2 (Kanodia et al. 2009), B. subtilis PCI219 (Kanda-Nambu et al. 2000) and L. fermentum ATCC9330 (Johnston and Diven. 1969) ALRs were not found in a data base, but those of B. anthracis ATCC14578, B. subtilis 168 and L. fermentum ATCC14931 were obtained from the UniProt data base and used as alternatives. Multiple alignments were performed using TCoffee (http://www.tcoffee.org/ Projects/tcoffee/).

\section{Plasmid construction}

The ORF containing the ALR gene in L. salivarius (Uniprot ID: Q1WV14) was amplified using PCR with chromosomal DNA from $L$. salivarius UCC118 and primers ALR-F 5'-ATATCATATGGTAATTGGAAGACATCG-3' (NdeI site is underlined) and ALR-R 5'-ATTCTCGAGCTACTTGTAAATTCTTGGAAC- $3^{\prime}$ (XhoI site is underlined). The PCR product was cloned between the NdeI and XhoI sites of pET-28a (Novagen, Darmstadt, Germany) to obtain pET-ALR.

To generate the $A L R^{A 131 K}$ mutant gene, the upstream and downstream regions of $A L R$ were amplified from pET-ALR using primers T7 promoter-F 5'-TAATAC GACTCACTATAGGG-3'and ALRA131K-R 5'-CATACC TGTGTCTAATTTTAGGTGGATCTTTAATCTTTG- $3^{\prime}$ (mutation bases are underlined) for the upstream, and primers ALRA131K-F 5'-CAAAGATTAAAGATCCACC TAAAATTAGACACACGTATG-3' (mutation bases are underlined) and T7 terminator-R 5'-GCTAGTTATTGCTCAGCGG-3 for the downstream. The two fragments were subsequently fused using overlap extension PCR to give the mutant gene $A L R^{A 131 K}$. The fused fragment was cloned between the NdeI and XhoI sites of pET-28a to give pET-ALR ${ }^{A 131 K}$.

\section{Preparation of recombinant proteins}

Escherichia coli BL21-CodonPlusTM(DE3)-RIPL cell (Stratagene, CA, USA) harboring pET-ALR was cultured in $5 \mathrm{~mL}$ of LB medium containing $50 \mathrm{mg} / \mathrm{L}$ kanamycin and $50 \mathrm{mg} / \mathrm{L}$ chloramphenicol overnight at $37^{\circ} \mathrm{C}$. The cells were then subcultured and induced using $100 \mathrm{~mL}$ of Overnight Expression medium containing 45 g/L Overnight Express ${ }^{\mathrm{TM}}$ Instant LB Medium (Novagen), $50 \mathrm{mg} / \mathrm{L}$ kanamycin and $50 \mathrm{mg} / \mathrm{L}$ chloramphenicol for $18 \mathrm{~h}$ at $25{ }^{\circ} \mathrm{C}$ with shaking $(180 \mathrm{rpm})$. The cells were then pelleted by centrifugation $\left(8500 \times g\right.$ for $10 \mathrm{~min}$ at $\left.4{ }^{\circ} \mathrm{C}\right)$ and resuspended in $20 \mathrm{mM}$ MOPS buffer (pH 7.0) containing $500 \mathrm{mM} \mathrm{NaCl}$, after which the suspension was sonicated and again centrifuged as described above. The supernatant was then filtered $(0.22 \mu \mathrm{m}$ pore size $)$, and the enzyme was purified on a Ni-NTA Agarose column (QIAGEN, Venlo, The Netherlands). The purified enzyme was dialyzed against 100 volumes of $20 \mathrm{mM}$ MOPS buffer (pH 7.0) containing $500 \mathrm{mM} \mathrm{NaCl}$ and $2.0 \mathrm{mM}$ EDTA for $12 \mathrm{~h}$ at $4{ }^{\circ} \mathrm{C}$ with two changes of the buffer solution. The resultant dialysate was then concentrated by ultrafiltration using an Amicon Ultra (Merck Millipore, MS, USA). The resultant enzyme solution was stored in the presence of $50 \%$ glycerol at $-20{ }^{\circ} \mathrm{C}$. ALR ${ }^{\mathrm{A} 131 \mathrm{~K}}$ protein was prepared using the same procedure with pET- $A L R^{A 131 K}$. 


\section{ALR assays}

ALR and ALR $^{\mathrm{A} 131 \mathrm{~K}}$ activities were determined by measuring the initial velocity of $\mathrm{D}$-alanine formation from L-alanine using ultra-performance liquid chromatography (UPLC) (Waters, Tokyo, Japan). The standard reaction mixture $(0.1 \mathrm{~mL})$ containing $100 \mathrm{mM} \mathrm{MES} \mathrm{buffer}(\mathrm{pH}$ 7.0), $20 \mathrm{mM}$ L-alanine, $0.05 \mathrm{mM}$ pyridoxal-5'-phosphate (PLP) and $10 \%(\mathrm{v} / \mathrm{v})$ purified enzyme solution. The enzyme reaction was run for $5 \mathrm{~min}$ at $30^{\circ} \mathrm{C}$ and was then stopped by adding $0.1 \mathrm{~mL}$ of $20 \%$ trichloroacetate. The UPLC analysis was performed with an ACQUITY UPLC TUV system consisting of a Waters Binary Solvent Manager, Sample Manager, FLR Detector and AccQ-Tag Ultra $2.1 \times 100$-mm column (Waters). The eluent flow rate was $0.20 \mathrm{~mL} / \mathrm{min}$, the column temperature was $45^{\circ} \mathrm{C}$, and the fluorescent wavelengths of the FLR detector were 350 and $450 \mathrm{~nm}$. The eluent was linearly graduated using $80 \%$ sodium acetate buffer (50 mM, pH 5.9) and $20 \%$ methanol. All enzyme assays were performed more than three times under the same conditions. Mean values and standard deviations were calculated from each assay.

\section{Effect of temperature on activity}

The effect of temperature on ALR and ALR ${ }^{\mathrm{A} 131 \mathrm{~K}}$ activities was examined using the standard reaction mixture and varying the temperature between 20 and $60{ }^{\circ} \mathrm{C}$ in presence and absence of $1 \mathrm{mM}$ acetate.

\section{Effect of $\mathrm{pH}$ on activity}

The effect of $\mathrm{pH}$ on ALR and ALR ${ }^{\mathrm{A} 131 \mathrm{~K}}$ activities was examined by measuring their activities under standard reaction conditions using different $\mathrm{pH}$ buffers in presence and absence of $1 \mathrm{mM}$ acetate. The buffers used for the assays were $100 \mathrm{mM}$ citrate $(\mathrm{pH} 4.0-5.5), 100 \mathrm{mM}$ MES (pH 5.5-7.0), $100 \mathrm{mM}$ Tris- $\mathrm{HCl}(\mathrm{pH} \mathrm{7.0-9.0)} \mathrm{and}$ $100 \mathrm{mM}$ sodium carbonate ( $\mathrm{pH}$ 9.0-11.0).

\section{Effect of various carboxylates on enzyme activity}

The effects of various carboxylates and related carboxylates containing acetate, propionate, butyrate, D, L-lactate, citrate, D, L-glutamate, D, L-aspartate, pyruvate, 2-oxoglutarate, oxaloacetate succinate and fumarate on ALR and ALR ${ }^{\mathrm{A} 131 \mathrm{~K}}$ activities were examined. All carboxylates used in this study were sodium salts or were neutralized with sodium hydroxide before use. The carboxylates $(1 \mathrm{mM})$ were added to the standard reaction mixture, and the rate of $\mathrm{L}$-alanine racemization was determined using the UPLC method as described above.

\section{Kinetic analysis}

Steady state kinetic analyses of ALR and $\mathrm{ALR}^{\mathrm{A} 131 \mathrm{~K}}$ were performed using various concentrations of $\mathrm{L}$-alanine in the presence of several concentrations of acetate. Initial velocity was measured using UPLC to determine the rate of conversion of $\mathrm{L}$-alanine to $\mathrm{D}$-alanine. The L-alanine concentrations used were 6.67, 10.0, 13.3, 20.0 and $40.0 \mathrm{mM}$, and the acetate concentrations were $1.00,10.0$, 20.0 and $40.0 \mathrm{mM}$.

\section{Results}

Primary sequence and amino acid composition of ALRs

from $L$. salivarius and other sources

We found a gene homologous (Q1WV14 in Uniprot) with ALR in an L. salivarius DNA database, and compared amino acid compositions of $L$. salivarius with other sources of ALRs (Table 1). The amino acid composition of the L. salivarius ALR was different from those of other ALRs in contents of arginine and lysine. However, affections to characteristics of $L$. salivarius ALR by these differences are unclear. Thus we aligned and compared the deduced amino acid sequence with those of ALRs from six other sources (Fig. 1). Although L. salivarius ALR showed relatively low overall sequence homology with ALRs from B. anthracis Sterne 43F2 (35.0 \%), B. pseudofirmus OF4 (26.1\%), B. subtilis 168 (34.6\%), G. stearothermophilus IFO 12550 (35.6\%) and P. putida YZ-26 (20.4\%), the two catalytic bases in the active site, $\mathrm{K} 40$ and Y267, were strictly conserved (Tanizawa et al. 1988; Shaw et al. 1997; Watanabe et al. 2002). In addition, among the four residues (K129, R138, M314 and D315) reportedly responsible for the binding of carboxylates such as acetate and propionate, which are specific inhibitors in the case of ALRs from Bacillus and Geobacillus species (Morollo et al. 1999; Kanodia et al. 2009), R138, M314 and D315 are conserved in the sequence of L. salivarius ALR. On the other hand, K129 is replaced by A131 in L. salivarius ALR, which suggests carboxylates may exert a different effect on L. salivarius ALR.

\section{Purification of $L$. salivarius ALR and $A L R^{A 131 K}$ from recombinant $E$. coli}

We cloned the $L$. salivarius ALR gene (Q1WV14 in Uniprot) and its substitution mutant, $A L R^{A 131 K}$, to obtain recombinant $E$. coli BL21-CodonPlusTM(DE3)-RIPL cells containing a hybrid plasmid harboring Q1WV14 or its $A L R^{A 131 K}$ mutant gene. Both expression products were purified to homogeneity using one-step Ni-NTA agarose column chromatography with high yields of 60.7 and $51.6 \%$, respectively. Both his-tagged recombinant proteins were exhibited single band located with estimated molecular mass of $43 \mathrm{kDa}$ (molecular mass of $L$. salivarius ALR from primary amino acid sequence is about $41 \mathrm{kDa}$ ). The activity of $\operatorname{ALR}^{\mathrm{A} 131 \mathrm{~K}}$ was $438 \pm 6.25 \mu \mathrm{mol} / \mathrm{min} \mathrm{mg}$, much higher than that of the ALR $(161 \pm 5.83 \mu \mathrm{mol} / \mathrm{min} \mathrm{mg})$ under the standard assay conditions. 
Table 1 Amino acid composition of L. salivarius ALR with other ALRs

\begin{tabular}{|c|c|c|c|c|c|c|c|}
\hline \multirow[t]{2}{*}{ Amino acid } & \multicolumn{7}{|c|}{ Number of residues per subunit } \\
\hline & L.sal & L.fer & P.put & B. ant & B.pse & B. sub & G. ste \\
\hline Alanine & 33 & 41 & 51 & 32 & 36 & 37 & 39 \\
\hline Arginine & 14 & 23 & 27 & 20 & 17 & 21 & 30 \\
\hline Asparagine & 15 & 8 & 19 & 15 & 11 & 14 & 9 \\
\hline Aspartate & 19 & 16 & 21 & 19 & 21 & 18 & 22 \\
\hline Cystein & 6 & 4 & 2 & 1 & 5 & 5 & 4 \\
\hline Glutamate & 14 & 15 & 14 & 8 & 9 & 8 & 10 \\
\hline Glutamine & 27 & 27 & 22 & 30 & 27 & 28 & 24 \\
\hline Glycine & 31 & 32 & 34 & 28 & 25 & 30 & 26 \\
\hline Histidine & 10 & 7 & 11 & 8 & 13 & 11 & 16 \\
\hline Isoleucine & 29 & 15 & 14 & 33 & 24 & 23 & 24 \\
\hline Leucine & 30 & 36 & 42 & 31 & 35 & 38 & 39 \\
\hline Lysine & 28 & 15 & 15 & 20 & 17 & 29 & 13 \\
\hline Methionine & 11 & 12 & 11 & 6 & 11 & 14 & 10 \\
\hline Phenylalanine & 12 & 13 & 13 & 21 & 13 & 14 & 16 \\
\hline Proline & 11 & 16 & 12 & 17 & 14 & 15 & 23 \\
\hline Serine & 20 & 15 & 25 & 16 & 29 & 19 & 17 \\
\hline Threonine & 18 & 23 & 25 & 25 & 22 & 20 & 19 \\
\hline Tryptophan & 4 & 3 & 4 & 6 & 0 & 4 & 5 \\
\hline Tyrosine & 12 & 15 & 9 & 16 & 12 & 13 & 14 \\
\hline Valine & 27 & 37 & 38 & 37 & 28 & 28 & 28 \\
\hline
\end{tabular}

L. sal L. salivarius UCC 118, L. fer L. fermentum ATCC14931, P. put P. putida YZ-26, B. ant B. anthracis Sterne 43F2, B. pse B. pseudofirmus OF4, B. sub B. subtilis PCI 219, G. ste G. stearothermophilus IFO 12550

\section{Effect of temperature on activity}

The effects of temperatures between 20 and $60{ }^{\circ} \mathrm{C}$ on the activities of purified ALR and $\mathrm{ALR}^{\mathrm{A} 131 \mathrm{~K}}$ were examined using $20 \mathrm{mM} \mathrm{L}$-alanine as the substrate in the presence and absence of $1 \mathrm{mM}$ acetate (Fig. 2a, b). The maximum activity of ALR without acetate was observed at $35{ }^{\circ} \mathrm{C}$, but shifted to $50{ }^{\circ} \mathrm{C}$ in the presence of $1 \mathrm{mM}$ acetate (Fig. 2a). Moreover, the activity of ALR in the presence of $1 \mathrm{mM}$ acetate at $50{ }^{\circ} \mathrm{C}$ was much higher than in its absence at $35{ }^{\circ} \mathrm{C}(317 \pm 5.72 \mu \mathrm{mol} / \mathrm{min} \mathrm{mg}$ vs. $178 \pm 2.04 \mu \mathrm{mol} / \mathrm{min} \mathrm{mg})$. In the absence of acetate, ALR activity was completely lost at $55{ }^{\circ} \mathrm{C}$, but it exhibited about $71 \%$ relative activity in the presence of $1 \mathrm{mM}$ acetate. By contrast, $1 \mathrm{mM}$ acetate had little or no effect on the temperature dependence of $\mathrm{ALR}^{\mathrm{A} 131 \mathrm{~K}}$ activity, and maximum $\mathrm{ALR}^{\mathrm{A} 131 \mathrm{~K}}$ activity was observed at $45{ }^{\circ} \mathrm{C}$ in presence or absence of acetate (Fig. 2b).

\section{Effect of $\mathrm{pH}$ on activity}

The effect of $\mathrm{pH}$ on ALR and $\mathrm{ALR}^{\mathrm{A} 131 \mathrm{~K}}$ activities was examined at $\mathrm{pH} 4.0-11.0$ in the presence and absence of $1 \mathrm{mM}$ acetate (Fig. 3a, b). ALR showed maximum activity at around $\mathrm{pH} 8.0$ in presence and absence of $1 \mathrm{mM}$ acetate. In addition, the relative activity of ALR was slightly increased by the addition of acetate. On the other hand,
ALR $^{\mathrm{A} 131 \mathrm{~K}}$ exhibited maximum activity at around $\mathrm{pH}$ 9.0, and $\mathrm{ALR}^{\mathrm{A} 131 \mathrm{~K}}$ activity was unaffected by $1 \mathrm{mM}$ acetate at any $\mathrm{pH}$.

\section{Kinetic analyses of $L$. salivarius ALR}

The initial velocity of $\mathrm{D}$-alanine formation from $\mathrm{L}$-alanine catalyzed by ALR was measured at several L-alanine concentrations in the presence of five concentrations of acetate. The resultant Lineweaver-Burk plots of the relation between the L-alanine concentration and the initial velocity showed five straight lines (Fig. 4a, b). Although ALR was strongly activated by the addition of $1 \mathrm{mM}$ acetate, the activation level was reduced by the addition of acetate concentrations above 10 , and $40 \mathrm{mM}$ acetate greatly inhibited ALR activity at all L-alanine concentrations (Fig. 4a). By contrast, ALR ${ }^{\mathrm{A} 131 \mathrm{~K}}$ activity was inhibited or unaffected at all the acetate contractions tested (1-40 mM). The $K_{\mathrm{m}}$ values of ALR and ALR ${ }^{\mathrm{A} 131 \mathrm{~K}}$ for $\mathrm{L}$-alanine in absence of acetate were 11.5 and $9.20 \mathrm{mM}$, respectively. The $V_{\max }$ of ALR and ALR ${ }^{\mathrm{A} 131 \mathrm{~K}}$ in absence of acetate were 272 and $751 \mu \mathrm{mol} / \mathrm{min} \mathrm{mg}$, respectively.

\section{Effect of different carboxylates on the activity}

We also tested the effect of carboxylates other than acetate on the activities of ALR and $\mathrm{ALR}^{\mathrm{A} 131 \mathrm{~K}}$ (Fig. 5). 


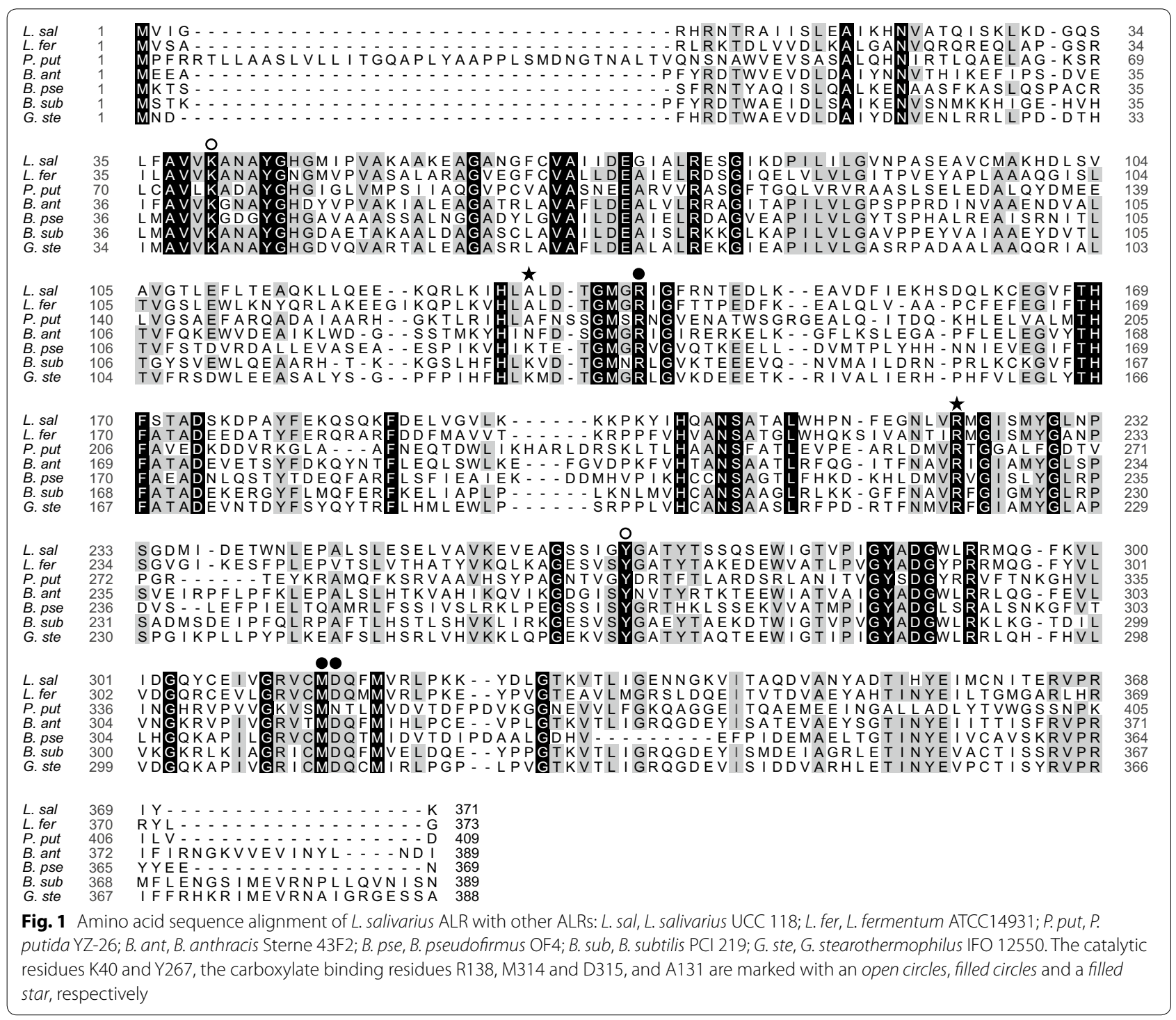

$\mathrm{ALR}^{\mathrm{A} 131 \mathrm{~K}}$ was inhibited to a greater degree than ALR by several of the carboxylates tested. Although propionate and butyrate are reportedly strong inhibitors of Bacillus and Geobacillus ALRs (Morollo et al. 1999; Kanodia et al. 2009), they strongly activated L. salivarius ALR. By contrast, both propionate and butyrate strongly inhibited $\mathrm{ALR}^{\mathrm{A} 131 \mathrm{~K}}$. ALR and $\mathrm{ALR}^{\mathrm{A} 131 \mathrm{~K}}$ were both inhibited by $\mathrm{D}$, L-lactate, though ALR was inhibited to a lesser degree than $\mathrm{ALR}^{\mathrm{A} 131 \mathrm{~K}}$. In addition, succinate, pyruvate, 2-oxoglutarate, oxaloacetate and aspartate also more strongly inhibited ALR ${ }^{\mathrm{A} 131 \mathrm{~K}}$ than ALR.

\section{Discussion}

To better understand the mechanism responsible for the high yield of D-alanine in L. salivarius, we characterized the ALR expressed by L. salivarius, which may be entirely responsible for its $\mathrm{D}$-alanine production. We found that the fundamental properties of this enzyme, including its temperature and $\mathrm{pH}$ optima and kinetic parameters, are similar to those of ALRs from other sources such as B. pseudofirmus and P. putida (Ju et al. 2009; Liu et al. 2012). Nonetheless, the sequence homologies between L. salivarius ALR and the ALRs from other sources were not high, and the L. salivarius enzyme was activated by several short-chain carboxylates (acetate, propionate and butyrate) that inhibit other ALRs. In particular, this activation is in contrast G. stearothermophilus ALR, which is clearly inhibited by both acetate and propionate (Morollo et al. 1999).

Six amino acid residues are responsible for the activity of G. stearothermophilus ALR (Morollo et al. 1999). Among the corresponding residues in L. salivarius ALR, five are conserved, but K129 of G. stearothermophilus ALR is replaced by A131 in L. salivarius (Fig. 1). We 

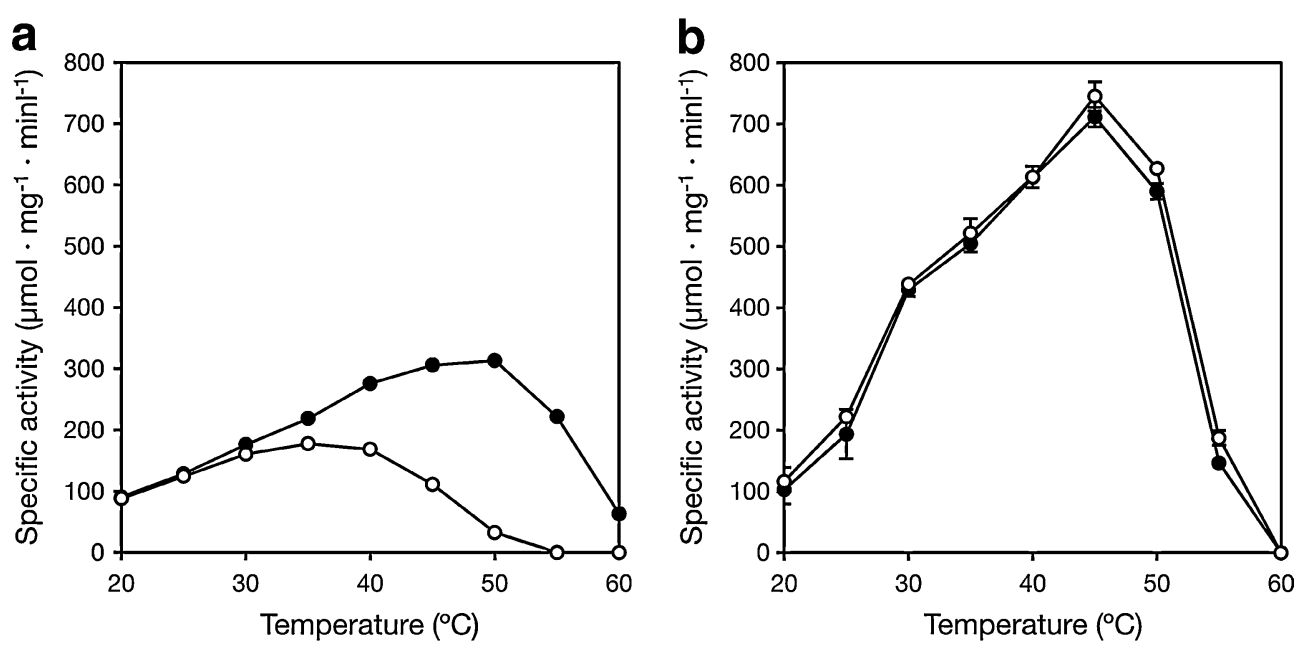

Fig. 2 a, b Effect of temperature on ALR and $\operatorname{ALR}^{\mathrm{A} 131 \mathrm{~K}}$ activities. ALR $(\mathbf{a})$ and $\operatorname{ALR}^{\mathrm{A} 131 \mathrm{~K}}(\mathbf{b})$ activities were assayed for 5 min at the indicated temperatures and pH 7.0 (MES buffer) using $20 \mathrm{mM} \mathrm{L-alanine} \mathrm{as} \mathrm{the} \mathrm{substrate} \mathrm{with} \mathrm{and} \mathrm{without} 1 \mathrm{mM}$ acetate. For ALR, the maximum rates with and without acetate were $317 \pm 5.72$ and $178 \pm 2.04 \mu \mathrm{mol} / \mathrm{min} \mathrm{mg}$, respectively $(n=3)$. For $\mathrm{ALR}^{\mathrm{A} 131 \mathrm{~K}}$, the maximum rates with and without acetate were $711 \pm 16.0$ and $745 \pm 23.4 \mu \mathrm{mol} / \mathrm{min} \mathrm{mg}$, respectively $(n=3)$. Open circles, without acetate; filled circles, with $1 \mathrm{mM}$ acetate
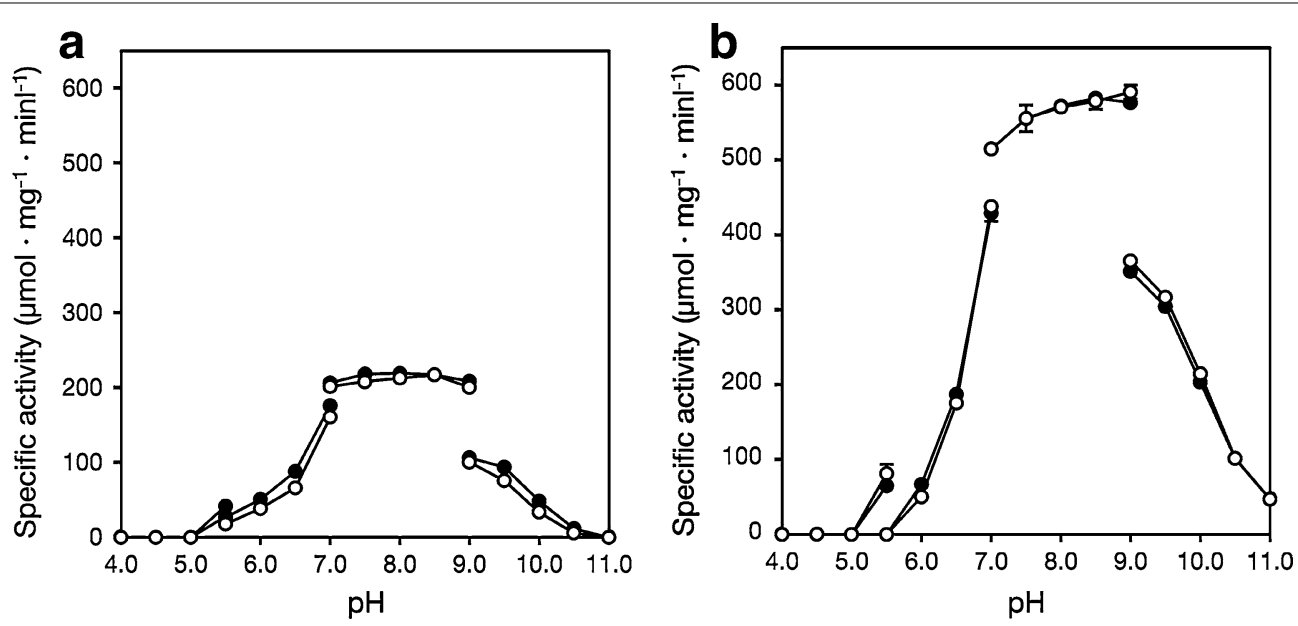

Fig. 3 a, b Effect of $\mathrm{pH}$ on $\mathrm{ALR}$ and $\mathrm{ALR}^{\mathrm{A} 131 \mathrm{~K}}$ activities. $\mathrm{ALR}(\mathbf{a})$ and $\operatorname{ALR}^{\mathrm{A} 131 \mathrm{~K}}(\mathbf{b})$ activities were assayed for 5 min at $30{ }^{\circ} \mathrm{C}$ and the indicated $\mathrm{pHs}$ using $20 \mathrm{mM} \mathrm{L}$-alanine as substrate. For ALR, the maximum rates with and without acetate were $219 \pm 3.61$ and $217 \pm 3.25 \mu \mathrm{mol} / \mathrm{min} \mathrm{mg}$, respectively $(n=3)$. For $A L R^{A 131 K}$, the maximum rates with and without acetate were $583 \pm 0.593$ and $591 \pm 9.10 \mu \mathrm{mol} / \mathrm{min} \mathrm{mg}$, respectively $(n=3)$. Open circles, without acetate; filled circles, with $1 \mathrm{mM}$ acetate. The buffers used were citrate (pH 4.0-5.5, MES (pH 5.5-7.0), Tris- HCl (pH 7.0-9.0) and carbonate ( $\mathrm{pH}$ 9.0-11.0)

therefore prepared and characterized an A131K variant of L. salivarius ALR. Interestingly the $\mathrm{ALR}^{\mathrm{A} 131 \mathrm{~K}}$ variant enzyme exhibited much greater activity than the wildtype enzyme; moreover, the activation by acetate and propionate disappeared, replaced by a typical mix-type inhibition same as previous reports of Bacillus ALR (Kanodia et al. 2009). This suggests acetate and propionate may be involved in the control of ALR activity, and that A131 may be responsible for the regulation of D-alanine synthesis in L. salivarius.
In G. stearothermophilus ALR, K129 reportedly interacts with R136, which binds to carboxylate and PLP oxygen through formation of carbamate (Morollo et al. 1999). This interaction between the $\mathrm{K} 129$ and R136 residues through carbamylation has also been seen in P. aeruginosa ALR (LeMagueres et al. 2003), and the same interaction occurs in Staphylococcus aureus ALR, though a sulfate ion substitutes for the carbamylation (Scaletti et al. 2012). Similarly, an equivalent N129 residue of B. anthracis ALR interacts with R136 through a chloride ion (Couñago et al. 

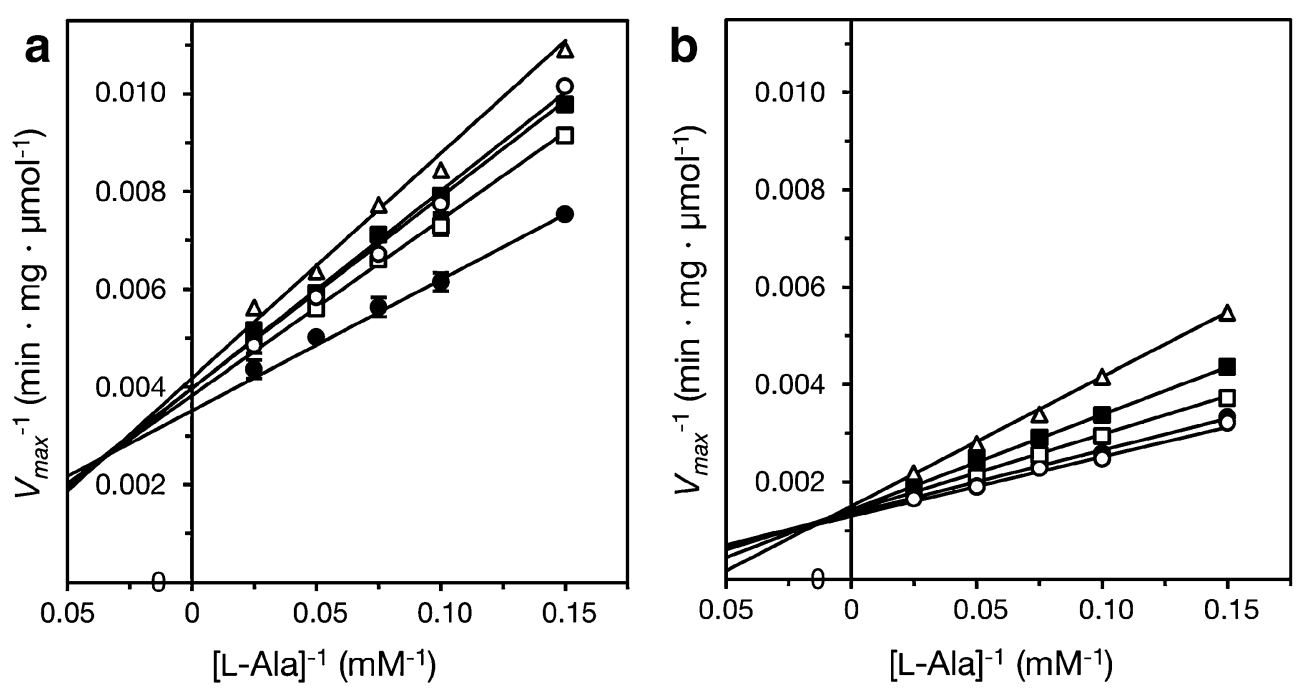

Fig. 4 Kinetics of acetate inhibition of $A L R$ and $A L R^{A 131 K}$. a, b ALR and $A L R^{A 131 K}$ were assayed for 5 min at $30^{\circ} \mathrm{C}$ and $p H 7.0$ (MES buffer) using various concentrations of L-alanine and acetate as the substrate and inhibitor, respectively. Shown are double reciprocal plots of the initial velocity of $\operatorname{ALR}(\mathbf{a})$ or $\mathrm{ALR}^{\mathrm{A} 131 \mathrm{~K}}(\mathbf{b})$ against L-alanine concentrations at several concentrations of acetate ( $\mathrm{n}=3$ for each enzyme). Open circles, without acetate; filled circles, $1.0 \mathrm{mM}$ acetate; open squares, $10.0 \mathrm{mM}$ acetate; filled squares, $20.0 \mathrm{mM}$ acetate; open triangles, $40.0 \mathrm{mM}$ acetate

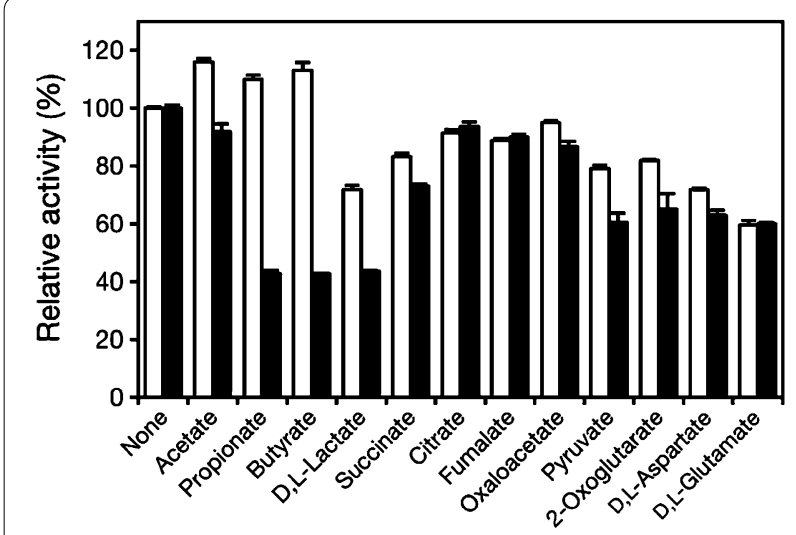

Additive carboxylates (1 $\mathrm{mM})$

Fig. 5 Effect of various carboxylates on ALR and ALR ${ }^{A 131 \mathrm{~K}}$ activities. ALR and $A L R^{A 131 K}$ were assayed for 5 min at $30^{\circ} \mathrm{C}$ and $\mathrm{pH} 7.0$ (MES buffer) using $20 \mathrm{mM}$ L-alanine as the substrate in the presence of the indicated carboxylates $(1 \mathrm{mM})$. The specific activities of ALR and $\mathrm{ALR}^{\mathrm{A} 131 \mathrm{~K}}$ at $100 \%$ were $171 \pm 0.559$ and $527 \pm 5.17 \mu \mathrm{mol} / \mathrm{min} \mathrm{mg}$ respectively $(n=3)$. Open bars, ALR activities; filled bars, ALR ${ }^{A 131 K}$ activities

2009). From these reports, it appears that there is often an interaction between K129 or N129 and R136 mediated in various ways within ALR. However the alanine side chain has no charge, so there is no interaction between A131 and R138 in L. salivarius ALR (which corresponds to R136 in Bacillus ALR). Consequently, R138 of L. salivarius ALR is probably poorly ordered and what would be the carboxyl group binding site is unstable. Acetate may stabilize $L$. salivarius ALR by binding to the carboxyl group binding site, and the activating effect of this structural stabilization may be more pronounced than acetate's inhibitory effect so that the net effect on L. salivarius ALR activity is stimulation. Consistent with that idea is the dramatic increase in ALR activity and stability seen in the A131K variant (Fig. 2), as well as the activating and inhibitory effects of acetate on ALR activity (Fig. 4). These stabilizing effect of competitive inhibitors were found in other enzymes (Burton 1951; Alvaro et al. 1991). A more precise explanation of the structural basis of the activation and/ or stabilization of $L$. salivarius ALR will require analysis of its crystal structure.

Zalan et al. reported the robust production of organic acids such as lactate and acetate by various Lactobacillus species (Zalán et al. 2010). In addition, propionate and butyrate are also produced by some Lactobacillus strains (Liong and Shah 2005; Pereira et al. 2003). Notably, when milk and Jerusalem artichoke juice are used for the growth medium, lactate production is depressed in many Lactobacillus strains, whereas acetate production is enhanced. As a result, the acetate concentration in cells from some Lactobacillus strains is higher than the lactate concentration, particularly under aerobic culture conditions (Bobillo and Marshall 1991; Cselovszky et al. 1992). This suggests that carboxylates such as acetate, propionate and butyrate might play regulatory roles affecting D-alanine production in Lactobacillus strains, through details of the control of ALR activity remain to be determined. 


\section{Abbreviations}

ALR: alanine racemase; $A L R^{A 131 K}$ : alanine racemase $A 131 \mathrm{~K}$ variant; PLP: pyridoxal 5'-phosphate; UPLC: ultra-performance liquid chromatography.

\section{Authors' contributions}

HS, KD and T Ohshima designed the study. JY performed a part of plasmid constructions and protein purifications. YS performed a part of UPLC analyses. JK performed main experiments and wrote the manuscript. T Ohmori performed UPLC analyses for additional data. All authors read and approved the final manuscript.

\section{Author details}

${ }^{1}$ Microbial Genetics Division, Institute of Genetic Resources, Faculty of Agriculture, Kyushu University, Fukuoka 812-8581, Japan. ${ }^{2}$ Applied Molecular Microbiology and Biomass Chemistry Bioscience and Biotechnology, Faculty of Agriculture, Kyushu University, Fukuoka 812-8581, Japan. ${ }^{3}$ Department of Biomedical Engineering, Faculty of Engineering, Osaka Institute of Technology, 5-16-1 Omiya, Asahi-ku, Osaka 535-8585, Japan. ${ }^{4}$ Functional Genomics of Extremophiles, Faculty of Agriculture, Graduate School, Kyushu University, Fukuoka 812-8581, Japan. ${ }^{5}$ Present Address: Department of Biomedical Engineering, Faculty of Engineering, Osaka Institute of Technology, 5-16-1 Ohmiya, Asahi-ku, Osaka 535-8585, Japan.

\section{Acknowledgements}

This work was supported by a grant for Promotion of Basic Research Activities for Innovate Bioscience from the Bio-oriented Technology Research Advancement Institution (BRAIN, Tokyo) and in part Kobayashi International Scholarship Foundation (Tokyo).

\section{Competing interests}

The authors declare that they have no competing interests.

Received: 18 December 2014 Accepted: 24 December 2014 Published online: 24 October 2015

\section{References}

Alvaro G, Fernandez-Lafuente R, Blanco RM, Guisán JM (1991) Stabilizing effect of penicillin $\mathrm{G}$ sulfoxide, a competitive inhibitor of penicillin $\mathrm{G}$ acylase: its practical applications. Enzyme Microb Technol 13:210-214. doi:10.1016/0141-0229(91)90130-3

Bobillo M, Marshall VM (1991) Effect of salt and culture aeration on lactate and acetate production by Lactobacillus plantarum. Food Microbiol 8:153-160. doi:10.1016/0740-0020(91)90008-P

Burton K (1951) The stabilization of D-amino-acid oxidase by flavin-adenine dinucleotide, substrates and competitive inhibitors. Biochem J 48:458-467

Couñago R, Davlieva M, Strych U, Hill R, Krause KL (2009) Biochemical and structural characterization of alanine racemase from Bacillus anthracis (Ames). BMC Struct Biol 9:53. doi:10.1186/1472-6807-9-53

Cselovszky J, Wolf G, Hammes WP (1992) Production of formate, acetate, and succinate by anaerobic fermentation of Lactobacillus pentosus in the presence of citrate. Appl Microbiol Biotechnol 37:94-97. doi:10.1007/ BF00174210

Erbe T, Brückner H (2000) Chromatographic determination of amino acid enantiomers in beers and raw materials used for their manufacture. J Chromatogr A 881:81-91. doi:10.1016/S0021-9673(00)00255-7

Heijenoort JV (2001) Recent advances in the formation of the bacterial peptidoglycan monomer unit. Nat Prod Rep 18:503-519. doi:10.1039/ A804532A

Hochbaum Al, Kolodkin-Gal I, Foulston L, Kolter R, Aizenberg J, Losick R (2011) Inhibitory effects of D-amino acids on Staphylococcus aureus biofilm development. J Bacteriol 193:5616-5622. doi:10.1128/JB.05534-11

Inagaki K, Tanizawa K, Badet B, Walsh CT, Tanaka H, Soda K (1986) Thermostable alanine racemase from Bacillus stearothermophilus: molecular cloning of the gene, enzyme purification, and characterization. Biochemistry 25:3268-3274. doi:10.1021/bi00359a028
Johnston MM, Diven WF (1969) Studies on amino acid racemases. I. Partial purification and properties of the alanine racemase from Lactobacillus fermenti. J Biol Chem 244:5414-5420

Ju J, Xu S, Wen J, Li G, Ohnishi K, Xue Y, Ma Y (2009) Characterization of endogenous pyridoxal 5'-phosphate-dependent alanine racemase from Bacillus pseudofirmus OF4. J Biosci Bioeng 107:225-229. doi:10.1016/j. jbiosc.2008.11.005

Kanda-Nambu K, Yasuda Y, Tochikubo K (2000) Isozymic nature of spore coatassociated alanine racemase of Bacillus subtilis. Amino Acids 18:375-387. doi:10.1007/s007260070076

Kanodia S, Agarwal S, Singh P, Agarwal S, Singh P, Bhatnagar R (2009) Biochemical characterization of alanine racemase: a spore protein produced by Bacillus anthracis. BMB Rep 42:47-52

Kobayashi J, Shimizu Y, Mutaguchi Y, Doi K, Ohshima T (2013) Characterization of D-amino acid aminotransferase from Lactobacillus salivarius. J Mol Catal B Enzym 94:15-22. doi:10.1016/j.molcatb.2013.04.013

Kolodkin-Gal I, Romero D, Cao S, Clardy J, Kolter R, Losick R (2010) D-amino acids trigger biofilm disassembly. Science 328:627-629. doi:10.1126/ science. 1188628

Kullman JP, Chen X, Armstrong DW (1999) Evaluation of the enantiomeric composition of amino acids in tobacco. Chirality 11:669-673. doi:10.1002/(SICI)1520-636X(1999)11:8<669:AID-CHIR10>3.0.CO;2-8

LeMagueres P, Im H, Dvorak A, Strych U, Benedik M, Krause KL (2003) Crystal structure at $1.45 \AA$ resolution of alanine racemase from a pathogenic bacterium, Pseudomonas aeruginosa, contains both internal and external aldimine forms. Biochemistry 42:14752-14761. doi:10.1021/bi030165v

Liong MT, Shah NP (2005) Production of organic acids from fermentation of mannitol, fructooligosaccharide and inulin by a cholesterol removing Lactobacillus acidophilus strain. J Appl Microbiol 99:783-793. doi:10.1111/j.1365-2672.2005.02677.x

Liu JL, Liu XQ, Shi YW (2012) Expression, purification, and characterization of alanine racemase from Pseudomonas putida YZ-26. World J Microbiol Biotechnol 28:267-274. doi:10.1007/s11274-011-0816-1

Morollo AA, Petsko GA, Ringe D (1999) Structure of a michaelis complex analogue: propionate binds in the substrate carboxylate site of alanine racemase. Biochem 38:3293-3301. doi:10.1021/bi9822729

Mutaguchi Y, Ohmori T, Akano H, Doi K, Ohshima T (2013) Distribution of D-amino acids in vinegars and involvement of lactic acid bacteria in the production of D-amino acids. Springerplus 2:691. doi:10.1186/2193-1801-2-691

Pätzold R, Schieber A, Brückner H (2005) Gas chromatographic quantification of free $D$-amino acids in higher vertebrates. Biomed Chromatogr 19:466-473. doi:10.1002/bmc.515

Pereira DI, McCartney AL, Gibson GR (2003) An in vitro study of the probiotic potential of a bile-salt-hydrolyzing Lactobacillus fermentum strain, and determination of its cholesterol-lowering properties. Appl Environ Microbiol 69:4743-4752. doi:10.1128/AEM.69.8.4743-4752.2003

Rosso G, Takashima K, Adams E (1969) Coenzyme content of purified alanine racemase from Pseudomonas. Biochem Biophys Res Commun 34:34-140. doi:10.1016/0006-291X(69)90539-7

Scaletti ER, Luckner SR, Krause KL (2012) Structural features and kinetic characterization of alanine racemase from Staphylococcus aureus (Mu50). Acta Crystallogr D Biol Crystallogr 68:82-92. doi:10.1107/S0907444911050682

Shaw JP, Petsko GA, Ringe D (1997) Determination of the structure of alanine racemase from Bacillus stearothermophilus at 1.9-A resolution. Biochemistry 36:1329-1342. doi:10.1021/bi961856c

Tanizawa K, Ohshima A, Scheidegger A, Inagaki K, Tanaka H, Soda K (1988) Thermostable alanine racemase from Bacillus stearothermophilus: DNA and protein sequence determination and secondary structure prediction. Biochemistry 27:1311-1316. doi:10.1021/bi00404a033

Watanabe A, Yoshimura T, Mikami B, Hayashi H, Kagamiyama H, Esaki N (2002) Reaction mechanism of alanine racemase from Bacillus stearothermophilus: X-ray crystallographic studies of the enzyme bound with N-(5'phosphopyridoxyl) alanine. J Biol Chem 277:19166-19172. doi:10.1074/ jbc.M201615200

Zalán Z, Hudáček J, Štětina J, Chumchalová J, Halász A (2010) Production of organic acids by Lactobacillus strains in three different media. Eur Food Res Technol 230:395-404. doi:10.1007/s00217-009-1179-9 